\title{
Nutraceutical Improvement Increases the Protective Activity of Broccoli Sprout Juice in a Human Intestinal Cell Model of Gut Inflammation
}

\author{
Simonetta Ferruzza ${ }^{1,+}$, Fausta Natella ${ }^{1, \dagger}$, Giulia Ranaldi ${ }^{1}$, Chiara Murgia ${ }^{1, \ddagger}$, Carlotta Rossi ${ }^{1}$, \\ Kajetan Trošt ${ }^{2, \S}$, Fulvio Mattivi ${ }^{2}$, Mirella Nardini ${ }^{1}$, Mariateresa Maldini ${ }^{1,}$ I I , Anna Maria Giusti ${ }^{3}$, \\ Elisabetta Moneta ${ }^{1}$, Cristina Scaccini ${ }^{1}$, Yula Sambuy ${ }^{1}$, Giorgio Morelli ${ }^{1}$ and Simona Baima ${ }^{1, *}$ \\ 1 Food and Nutrition Research Centre, Consiglio per la ricerca in agricoltura e l'analisi dell'economia agraria, \\ Via Ardeatina 546, 00178 Rome, Italy; simonetta.ferruzza@crea.gov.it (S.F.); fausta.natella@crea.gov.it (F.N.); \\ giulia.ranaldi@crea.gov.it (G.R.); chiara.murgia@monash.edu (C.M.); carlottarossi22@hotmail.com (C.R.); \\ mirella.nardini@crea.gov.it (M.N.); mtmaldini@uniss.it (M.M.); elisabetta.moneta@crea.gov.it (E.M.); \\ cristina.scaccini@crea.gov.it (C.S.); yula.sambuy@crea.gov.it (Y.S.); giorgio.morelli@crea.gov.it (G.M.) \\ 2 Food Quality and Nutrition Department, Research and Innovation Centre, Fondazione Edmund Mach, \\ Via Edmund Mach 1, 38010 San Michele all'Adige (TN), Italy; kajo@wajdusna.net (K.T.); \\ fulvio.mattivi@fmach.it (F.M.) \\ 3 Department of Experimental Medicine, Section of Medical Physiopathology, Food Science and \\ Endocrinology, Sapienza University, P.le Aldo Moro 5, 00185 Rome, Italy; annamaria.giusti@uniroma1.it \\ * Correspondence: simona.baima@crea.gov.it; Tel.: +39-06-51494-453 \\ $+\quad$ These authors contributed equally to this work \\ $\ddagger$ Current address: Department of Nutrition and Dietetics, Monash University, 264 Ferntree Gully Road, \\ 3168 Vic, Australia \\ $\S$ Current address: Steno Diabetes Center A/S, Niels Steensens Vej 2, 2820 Gentofte, Denmark \\ I | Current address: Department of Chemistry and Pharmacy, University of Sassari, Via Muroni 23, \\ 07100 Sassari, Italy
}

Academic Editor: Dario Donno

Received: 23 June 2016; Accepted: 8 August 2016; Published: 12 August 2016

\begin{abstract}
Benefits to health from a high consumption of fruits and vegetables are well established and have been attributed to bioactive secondary metabolites present in edible plants. However, the effects of specific health-related phytochemicals within a complex food matrix are difficult to assess. In an attempt to address this problem, we have used elicitation to improve the nutraceutical content of seedlings of Brassica oleracea grown under controlled conditions. Analysis, by LC-MS, of the glucosinolate, isothiocyanate and phenolic compound content of juices obtained from sprouts indicated that elicitation induces an enrichment of several phenolics, particularly of the anthocyanin fraction. To test the biological activity of basal and enriched juices we took advantage of a recently developed in vitro model of inflamed human intestinal epithelium. Both sprouts' juices protected intestinal barrier integrity in Caco-2 cells exposed to tumor necrosis factor $\alpha$ under marginal zinc deprivation, with the enriched juice showing higher protection. Multivariate regression analysis indicated that the extent of rescue from stress-induced epithelial dysfunction correlated with the composition in bioactive molecules of the juices and, in particular, with a group of phenolic compounds, including several anthocyanins, quercetin-3-Glc, cryptochlorogenic, neochlorogenic and cinnamic acids.
\end{abstract}

Keywords: functional food; broccoli sprouts; Caco-2; intestinal permeability; inflammatory response; bioactive molecules; phenolic compounds; anthocyanins; sulforafane 


\section{Introduction}

Epidemiological data indicate that frequent fruit and vegetable consumption is associated with a reduction in morbidity and mortality from cardiovascular diseases, type 2 diabetes mellitus and several cancers [1-4], and this effect has been attributed to their high content in vitamins, minerals, polyphenols and other bioactive molecules. Indeed, several isolated phytochemicals have been shown to exert a potential health-promoting effect in different experimental systems [5-7]. However, studies with whole foods, rather than with isolated bioactive chemicals, are strongly recommended to account for the effects of possible interactions of different molecules within the context of the food matrix $[1,8]$. A common drawback of this type of study is the poor chemical characterization and the great qualitative and quantitative compositional variability of vegetable foods [8,9]. In fact, the metabolite content of a given fruit or vegetable depends on many different factors such as cultivar, geographical origin, agronomical practice, storage, processing and preparation. As sessile organisms, plants have evolved a high metabolic plasticity as a sophisticated adaptive defensive response mechanism to grow and survive under biotic and abiotic stresses [10,11]. While this flexibility contributes to the compositional variability that challenges the scientific assessment of the benefits of plant foods, the environmental response of plants can be exploited to enhance the content of specific health-related molecules, or classes of molecules, within the food matrix. In fact, most of the bioactives that have been shown to exert a protective role in animals are secondary metabolites, mainly phenolics, that plants synthetize to protect themselves from adverse environmental conditions. Therefore, elicitation, i.e., manipulation of growth conditions to trigger the synthesis and accumulation of bioactive secondary metabolites, can be considered a good strategy for functional enrichment of plant-derived foods [12]. Recently, by systematic evaluation of many different elicitors, we have identified sucrose as the elicitor that provides the most significant overall effect on phytochemical composition of young broccoli seedlings [13].

Broccoli, along with many other common vegetables such as cauliflower, kale, brussels sprouts etc. belonging to the Brassicaceae family, are considered to have a high health-promoting potential for their richness in vitamins, minerals, fibers, and bioactive secondary metabolites [14,15]. Among these, considerable attention has been given to glucosinolates (GLSs), a class of secondary metabolites synthetized almost exclusively by this plant family, and, in particular, to their hydrolysis products' isothiocyanates (ITCs) for their ability to induce phase II detoxification enzyme activities and anticancer potential [16,17]. Sprouts of Brassicaceae contain higher levels of phenolic compounds and GLSs than adult plants [18-20], and are increasingly becoming popular as natural functional foods.

Critical for the assessment of potentially health-related bioactivity of conventional or functionally enriched food extracts is the choice of a physiologically relevant experimental system and of appropriate endpoint(s) [8,21]. Although epidemiologic and intervention studies are absolutely required for evaluation of functional foods, it is generally recognized that properly designed animal and cell culture studies can help to elucidate mechanistic aspects of food/food component effects $[8,21]$.

The aim of this study was to functionally test the effects of phytochemical enrichment of broccoli sprouts elicited with sucrose on an intestinal cell model of gut inflammation. Since several bioactive secondary metabolites from Brassicaceae are reported to possess anti-inflammatory properties [22-24], we took advantage of a recently developed model of inflammatory stress in the human intestinal Caco-2 cell line [25] to compare the biological activity of juices, from both basal and elicited broccoli sprouts, characterized by different polyphenol, flavonoid and anthocyanin profiles. Pre-incubation of differentiated intestinal Caco-2 cells with these juices conferred protection from the inflammatory stress induced by tumor necrosis factor $\alpha(\mathrm{TNF} \alpha)$ under marginal zinc deficiency. A chemometric approach was used to correlate the protective effect of broccoli juices with their content in bioactives, detecting a significant association with the composition in anthocyanins and other polyphenolic compounds. 


\section{Results}

\subsection{Preparation of Basal and Enriched Broccoli Sprout Juices}

In this study, young broccoli seedlings (sprouts) were grown in a climatic chamber in which growth conditions can be easily controlled and modified. Biomass yield was higher for sprouts grown in basal condition (B) than for those in enriching condition (E) (12 g of seeds produced $116.26 \pm 8.58 \mathrm{~g}$ and $86.69 \pm 11.51 \mathrm{~g}$ of sprouts, respectively; mean $\pm \mathrm{SD}$ ). The sprouts grown in the two conditions were morphologically different: elongated with yellowish, unexpanded cotyledons in the case of B and short with expanded green and reddish cotyledon in the case of E (Figure 1). Immediately after harvesting, aqueous juices were prepared from sprouts with a slow rotating screw (cold press) as it had previously been shown that, when used to prepare juices from adult broccoli, it resulted in maximal recovery of polyphenols and in highest growth inhibitory effects on cancer cells, compared to centrifugal juicer or blender [26]. Aliquots of the juices were used for compositional analysis and functional testing on cell cultures (Figure 1).

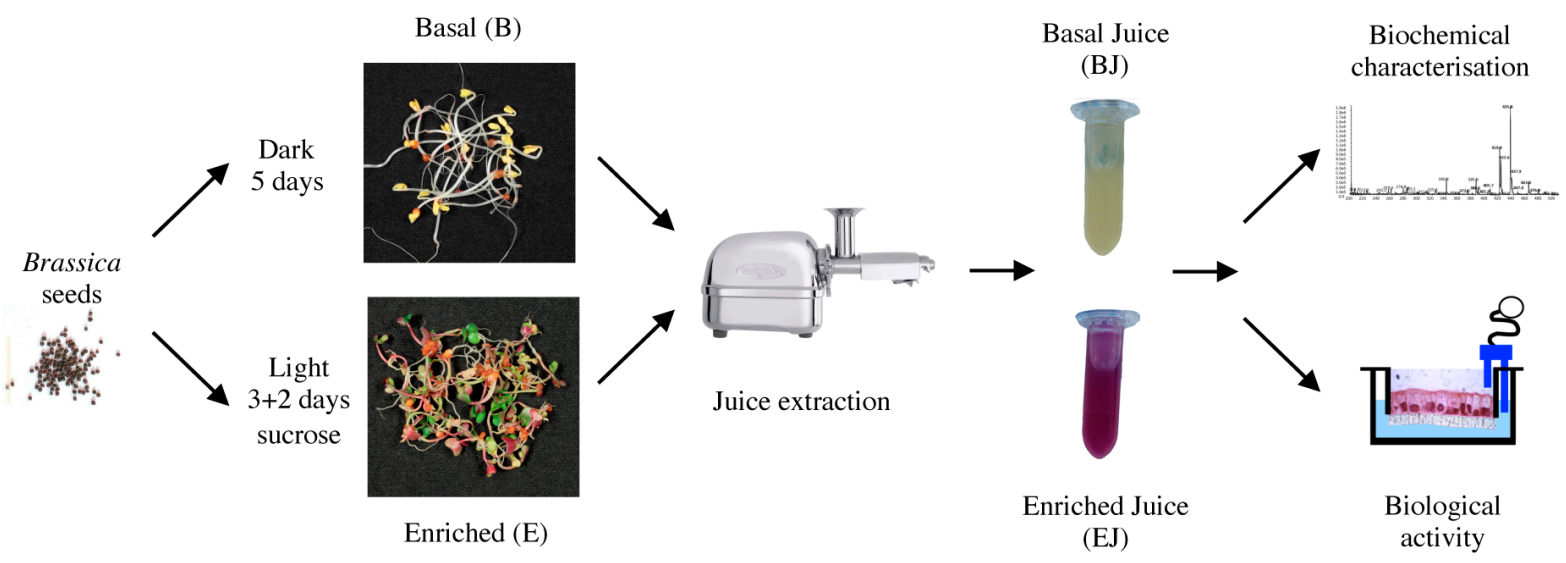

Figure 1. Assessment of growth conditions on composition and biological activity of broccoli sprouts. Schematic representation of the experimental workflow used to evaluate and compare the composition and the biological activity of juices prepared from broccoli sprouts grown under two different conditions.

\subsection{Compositional Analysis}

To characterize the phytochemical diversity induced by different growth conditions, LC-MS metabolomic fingerprinting data were used as descriptors of the composition of the broccoli sprout juices. Untargeted LC-MS metabolomic profiling analysis was carried out on three independent biological replicates of each type of juice in both negative and positive ion modes, yielding 598 and 855 features, respectively. Following the automated data mining and pre-treatment step of LC-MS metabolomic data, the intensity value of each anonymous peak was normalized by Z-score transformation. The datasets of the normalized variables were graphically visualized in Figure 2 . Statistical analysis of data distribution confirmed that the composition of the juices obtained from sprouts grown under basal (BJ) and enriching conditions (EJ) was significantly different $(p<0.0001)$. Targeted LC-MS analysis was then applied to compare the composition of BJ and EJ with respect to phytochemicals that can potentially affect the biological activity of sprouts (Table 1).

Sulforaphane (SFN), the major inducer of phase II enzymes, and SFN-nitrile, both derived from enzymatic conversion of glucoraphanin (the most abundant GLS present in B. oleracea sprouts [27]), were detected at similar levels in both BJ and EJ (Table 1). Glucoraphanin and other GLSs were not present in both BJ and EJ, as expected from myrosinase activation during juice preparation. The total content of different classes of phenolic compounds was found to be higher in EJ than in BJ, with a dramatic increase of the anthocyanin fraction (total polyphenols (TP) 1.6-fold, total flavonoids 
(TF) 2.6-fold, and total anthocyanins (TA) about 10-fold enrichment, respectively). Targeted LC-MS analysis allowed the detection and identification of 18 phenolic compounds and 14 anthocyanins (Table 1). The vast majority of the 18 polyphenols detected were found significantly increased in EJ. In particular, a dramatic difference was observed for neochlorogenic acid, with a concentration about 50 times higher, and for chlorogenic and caffeic acid, that both showed a 13-fold enrichment compared to BJ. Only four phenolic compounds, namely sinapic acid, syringic acid, 4-aminobenzoic acid, and syringaldehyde, showed an inverse trend, being significantly more abundant in BJ than in EJ. Among the 14 anthocyanins detected in EJ, only cyanidine-3-diglucoside-5-glucoside (Cy-3-dGlc-5-Glc) was found also in BJ, while the others were below detection level (Table 1).

Table 1. Targeted analysis of broccoli sprouts' juice content.

\begin{tabular}{|c|c|c|c|c|c|c|c|c|c|}
\hline & & \multicolumn{3}{|c|}{ Basal Juice } & \multicolumn{3}{|c|}{ Enriched Juice } & \multicolumn{2}{|l|}{ Fold } \\
\hline $\mathrm{TP}$ & Total Phenols (mg GAE/mL) & 1.86 & \pm & 0.24 & 3.01 & \pm & 0.34 & 1.6 & $* *$ \\
\hline TA & Total Anthocyanins ( $\mu \mathrm{g}$ Cy_3_GlcE/mL) & 4.29 & \pm & 0.48 & 40.15 & \pm & 15.28 & 9.4 & * \\
\hline SFN & Sulforaphane $(\mu \mathrm{g} / \mathrm{mL})$ & 19.37 & \pm & 2.65 & 21.90 & \pm & 1.57 & 1.1 & \\
\hline 4-ABA & 4-Aminobenzoic acid & 0.08 & \pm & 0.02 & 0.04 & \pm & 0.01 & 0.6 & \\
\hline CA & Caffeic acid & 0.01 & \pm & 0.01 & 0.19 & \pm & 0.06 & 13.5 & * \\
\hline Cat & Catechin & 2.37 & \pm & 0.24 & 3.06 & \pm & 0.20 & 1.3 & * \\
\hline ChlA & Chlorogenic acid & 0.08 & \pm & 0.02 & 1.11 & \pm & 0.37 & 13.5 & $*$ \\
\hline FA & Ferulic acid & 0.38 & \pm & 0.03 & 0.64 & \pm & 0.17 & 1.7 & \\
\hline IsoR3Glc & Isorhamnetin-3-Glc & 0.05 & \pm & 0.03 & 0.03 & \pm & 0.01 & 0.7 & \\
\hline NChlA & Neochlorogenic acid & 0.24 & \pm & 0.02 & 12.03 & \pm & 1.96 & 49.5 & $* * *$ \\
\hline ProCyB2 & Procyanidin B2 & 0.02 & \pm & 0.01 & 0.04 & \pm & 0.01 & 1.7 & \\
\hline Q3Glc & Quercetin-3-Glc & & n.d. & & 0.21 & \pm & 0.01 & & $* * *$ \\
\hline Q34diGlc & Quercetin-3.4-diGlc & 0.15 & \pm & 0.05 & 0.88 & \pm & 0.34 & 5.9 & * \\
\hline $\operatorname{Sin} \mathrm{A}$ & Sinapic acid & 38.01 & \pm & 12.02 & 25.59 & \pm & 7.12 & 0.7 & \\
\hline SinAl & Sinapyl alcohol & 0.15 & \pm & 0.07 & 0.33 & \pm & 0.04 & 2.2 & * \\
\hline SyrAld & Syringaldehyde & 0.05 & \pm & 0.01 & 0.02 & \pm & 0.01 & 0.4 & * \\
\hline SyrA & Syringic acid & 0.41 & \pm & 0.02 & 0.28 & \pm & 0.06 & 0.7 & $*$ \\
\hline \multicolumn{10}{|c|}{ Anthocyanins $(\mu \mathrm{g} / \mathrm{mL})^{1}$} \\
\hline Cy3_g & Cy_3_sinapoyl_diGlc_5_malonyl_Glc & & n.d. & & 0.37 & \pm & 0.08 & & $* *$ \\
\hline Cy3_h & Cy_3_feruloyl_diGlc_5_malonyl_Glc & & n.d. & & 0.29 & \pm & 0.01 & & $* * *$ \\
\hline Cy3_i & Cy_3_caffeyl_diGlc_5_malonyl_Glc & & n.d. & & 0.07 & \pm & 0.06 & & \\
\hline Cy3_1 & Cy_3_coumaryl_diGlc_5_malonyl_Glc & & n.d. & & 0.55 & \pm & 0.07 & & $* * *$ \\
\hline Cy3_m & Cy_3_sinapoyl_diGlc_5_Glc & & n.d. & & 0.94 & \pm & 0.11 & & $* * *$ \\
\hline Cy3_n & Cy_3_feruloyl_diGlc_5_Glc & & n.d. & & 0.85 & \pm & 0.20 & & $* *$ \\
\hline Cy3_o & Cy_3_coumaroyl_diGlc_5_Glc & & n.d. & & 0.84 & \pm & 0.08 & & $* * *$ \\
\hline Cy3_p & Cy_3_diGlc_5_Glc & 0.58 & \pm & 0.05 & 1.61 & \pm & 0.25 & 2.8 & $* *$ \\
\hline
\end{tabular}


A

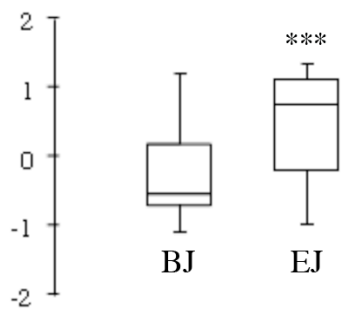

B

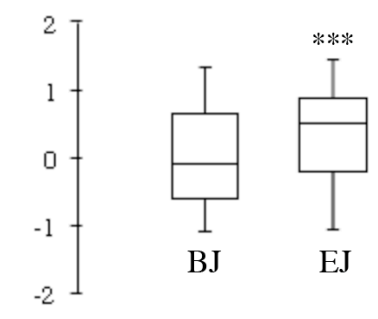

Figure 2. Box plot of LC-MS untargeted metabolomic fingerprinting. Distribution of LC-MS normalized (Z-scores) data from three biological replicates of juice from sprouts grown under two experimental conditions (basal, BJ; enriching, EJ). (A) Negative ion mode (mean values of $n=598$ peaks); (B) Positive ion mode (mean values of $n=855$ peaks). Center line shows the median; box limits indicate the 25th and 75th percentiles; whiskers extend to the most extreme data point within 1.5 times the interquartile range. ${ }^{* * *} p<0.0001 \mathrm{EJ}$ vs. BJ.

\subsection{In Vitro Testing of Biological Effects}

The gastro-intestinal mucosa is a selective barrier that regulates compounds' bioavailability and has a pivotal role in the interaction between food components and the organism. Thus, an intestinal cell model seems an appropriate choice to investigate in vitro the potentially beneficial effects of plant food preparations and the underlying molecular mechanisms. Upon differentiation on filter inserts, human intestinal Caco-2 cells form a polarized monolayer that separates two distinct compartments, corresponding in vivo to the intestinal lumen and the blood circulation, and display many of the physiological and morphological characteristics of intestinal absorptive enterocytes [28-31]. Addition of the food extract of interest to the apical (AP) compartment of this cell model challenged with pathological or toxic stimuli allows the study of the protective capacity of the food/food components under investigation [32,33].

We have recently demonstrated that Caco-2 cells with marginal zinc deficiency respond to the inflammatory cytokine TNF $\alpha$ undergoing a gradual increase in cell monolayer permeability that can easily be monitored by measuring the decrease in trans-epithelial electrical resistance (TEER) [25], a characteristic parameter of epithelial cell layers, reflecting the functionality of the tight junctions and the integrity of the cell monolayer. A decrease in TEER values is indicative of early sub-lethal cell toxicity [34,35]. This experimental model was exploited to assay the biological effects of broccoli sprouts' juices. Filter grown, differentiated Caco-2 cells were pre-incubated from the AP side for $14 \mathrm{~h}$ in medium containing different dilutions of BJ or EJ. After removal of juice-containing medium, cells were marginally zinc-depleted by incubation for $2 \mathrm{~h}$ with $N, N, N^{\prime}, N^{\prime}$-tetrakis(2-pyridylmethyl)ethane-1,2-diamine (TPEN) and subsequently challenged with $\mathrm{TNF} \alpha$ for $5 \mathrm{~h}$ (TPEN/TNF $\alpha$ treatment). As indicated in Figure 3, pretreatment with EJ, at all dilutions tested, determined a significant protection from the effects of TPEN/TNF $\alpha$ on TEER with respect to cells not exposed to the juice. The extent of protection was correlated to the amount of juice added and reached its maximum at a dilution of $250 \mu \mathrm{L} / \mathrm{mL}$. Pretreatment with BJ always resulted in lower effect compared to EJ and a significant protection was only observed at $250 \mu \mathrm{L} / \mathrm{mL}$. Thus, further experiments were conducted using juice pre-incubation at $250 \mu \mathrm{L} / \mathrm{mL}$. It is noteworthy that pre-treatment of cells with medium containing the same dilution of juices had no effect on TEER, indicating that both BJ and EJ alone did not affect epithelial integrity (Figure 3).

To compare the protective effects of BJ and EJ, time-course experiments were carried out, monitoring TEER values over $5 \mathrm{~h}$ of TNF $\alpha$ incubation. As shown in Figure 4, the protective ability of sprout juices was already significant after $3 \mathrm{~h}$ of TNF $\alpha$ exposure. However, at this time point, BJ and EJ displayed comparable protection, while at later times, EJ protection was significantly higher compared to that of BJ. 


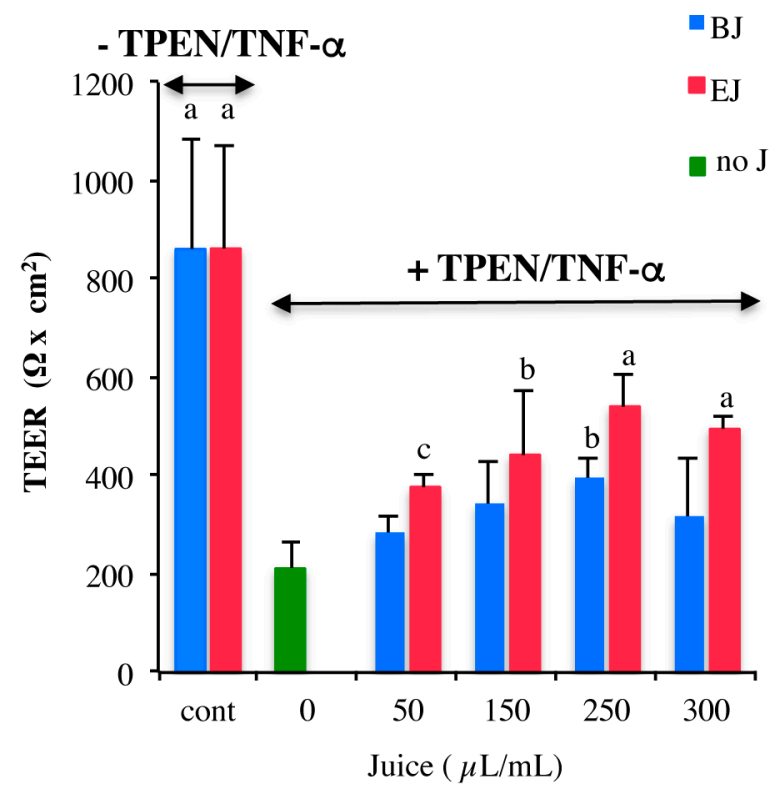

Figure 3. Broccoli sprout juices protect epithelial barrier integrity of zinc-depleted Caco-2 cells exposed to TNF $\alpha$. Caco-2 cells differentiated on filters for 21 days were pre-incubated for $14 \mathrm{~h}$ with experimental medium containing the indicated amount of broccoli juice in the AP compartment (red bars: EJ; blue bars: BJ; green bar: experimental medium without juice addition, noJ). Cells were then zinc deprived by TPEN incubation and exposed to TNF $\alpha$ for $5 \mathrm{~h}$. As control, a set of filters was pre-incubated with the addition of $250 \mu \mathrm{L} / \mathrm{mL}$ of BJ or EJ for $14 \mathrm{~h}$ and then maintained in experimental medium for the whole experiment. TEER values, measured at the end of the experiment, are expressed as means \pm SD from three experiments performed in triplicate. Statistical analysis was performed by one-way ANOVA followed by Fischer post hoc test. Different letters above bars indicate significant differences vs. TPEN $/ \mathrm{TNF} \alpha$-treated cells without juice pre-treatement (green bar). a: $p<0.0001$; b: $p<0.01$; c: $p<0.05$.

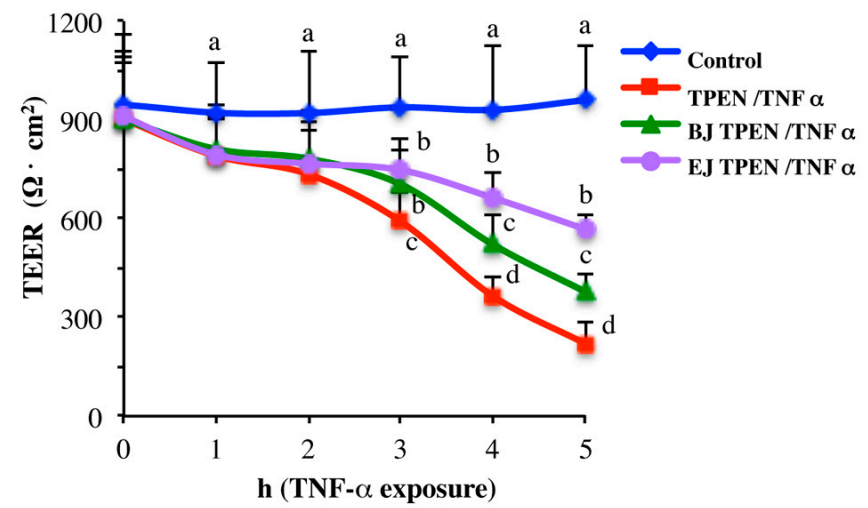

Figure 4. Time course of the protective effects of broccoli sprout juices in TPEN/TNF $\alpha$ treated Caco-2 cells. Caco-2 cells differentiated on filters for 21 days were pre-incubated for $14 \mathrm{~h}$ in experimental medium with BJ (green triangles), EJ (purple circles) or without juice (red squares) addition in the AP compartment. Cells were zinc deprived by TPEN incubation and exposed to TNF $\alpha$ except untreated control cells (blue diamonds) that were maintained in experimental medium throughout the experiment. TEER was monitored in the last $5 \mathrm{~h}$ of the experiment during TNF $\alpha$ treatment. Data are the mean $\pm \mathrm{SD}$ from three experiments performed in triplicate. One-way ANOVA was performed on mean-centered data followed by Fischer post hoc test. Different letters above bars indicate significant differences $(p<0.05)$ among treatments. 
To determine the reproducibility of the biological effects of the juices, three different batches of BJ and EJ (namely Juices 1, 2 and 3), prepared from independent sprout growths, were analyzed. As shown in Figure 5, all three batches of EJ, after $5 \mathrm{~h}$ of treatment, conferred a similar protection in preventing TEER reduction produced by TPEN/TNF $\alpha$ inflammatory stimulus. All three BJ protected significantly less than their corresponding EJ.

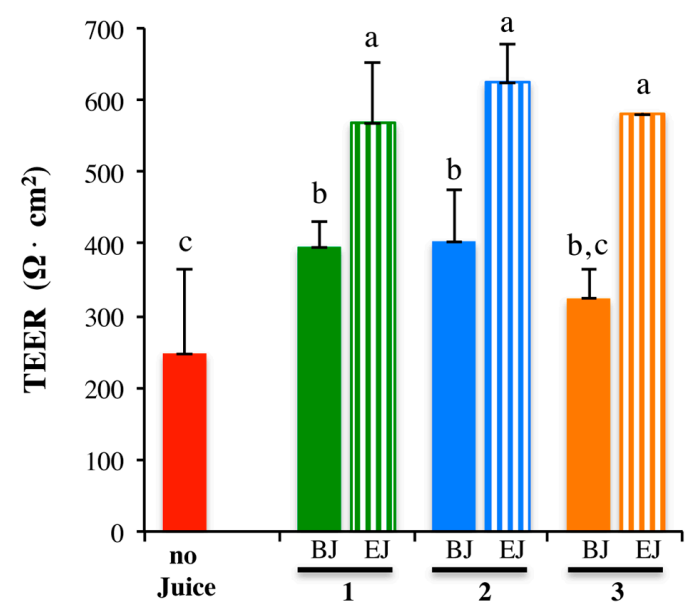

Figure 5. Juices from independendent sprouts growths show similar effects in TPEN/TNF $\alpha$ treated Caco-2 cells. Caco-2 cells differentiated on filters for 21 days were pre-incubated for $14 \mathrm{~h}$ in experimental medium with BJ (full bars) or EJ (striped bars) obtained from three indipendent sprouts growths (green, blue and orange bars) or without juice (red bar) addition in the AP compartment. Cells were then zinc deprived by TPEN incubation and exposed to TNF $\alpha$. TEER values were measured after $5 \mathrm{~h}$ of TNF $\alpha$ treatment. Statistical analysis was performed by one-way ANOVA followed by Fischer post hoc test. Different letters above bars indicate significant differences $(p<0.01)$ among treatments.

\subsection{Multivariate Analysis of Composition and Correlation with the Biological Effect}

To explore the relationship between the protective effect on Caco-2 cells subjected to inflammatory stimulus and the enrichment in bioactive phytochemicals, multivariate data analysis was performed, aimed at identifying the key drivers of the observed differences between BJ and EJ. To achieve this, Partial Least Square Regression (PLSR) was applied to model the relationship between quantitative data for the single phytochemicals listed in Table 1, as independent predictive variables (X), and the protective effect obtained in our cellular model, expressed as TEER at $5 \mathrm{~h}$, as dependent variables (Y). As reported in Table 2, the first two dimensions of the built PLSR model could explain 100\% of the variance for the cell protection attribute, namely TEER, using $92 \%$ of phytochemical content information. The first two principal components are illustrated in Figure 6. Notably, the 1st component (Factor-1 $=81 \%$ ) explained $92 \%$ of the biological effect of the samples, while the 2nd component (Factor-2 $=11 \%$ ) explained only a residual $8 \%$ of the biological effect. Juice samples were grouped on the plane according to sprout growth conditions. A clear separation was obtained along the first dimension, with samples from dark grown sprouts (BJ) positioned in the left quadrants, and samples from elicited sprouts (EJ) located in the right quadrants, while distribution of the samples on the second dimension (accounting only for $11 \%$ of the variance), indicated a residual limited biological variance between juices obtained from independent growths (Figure 6A). Interestingly, most of the phytochemicals measured were positioned on the right side of the plot contributing to the EJ description, except for sinapic acid, syringic acid, 4-aminobenzoic acid, syringaldehyde and isorhamnetin-3-glucoside, which were associated with BJ. The high weighted regression coefficients (BW) obtained from the estimated PLSR model identified the phytochemicals that significantly contributed to the differences observed in cell-protection effects (Table 2, Figure 6B). In particular, intestinal cell protection was positively correlated with procyanidin B2, cryptochlorogenic acid, neochlorogenic acid, quercetin-3-glucoside, 
cinnamic acid and five different cyanidine-3-glucoside, which could explain the correspondingly higher protective capacity of EJ compared to BJ, while a negative correlation was observed only with sinapic acid. The model was validated by full cross-validation. Pearson correlation coefficient and root mean square error for both calibration and validation of the model are shown in Table 2.
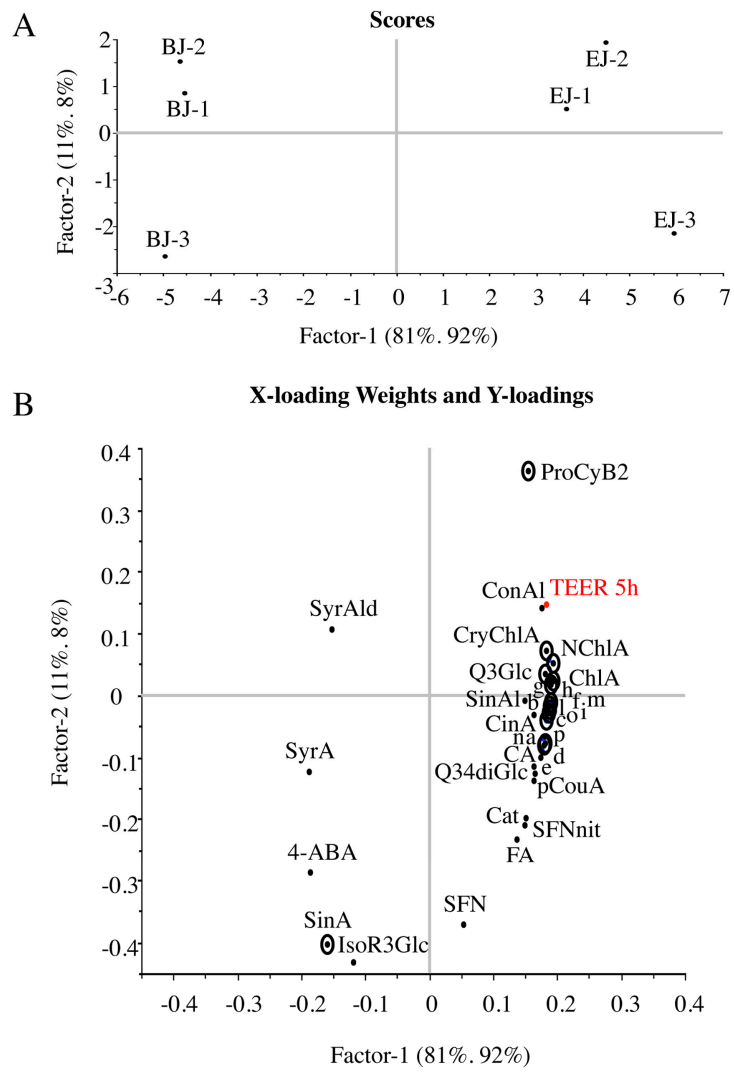

Figure 6. TPEN/TNF $\alpha$-treated Caco- 2 cell protection is correlated to phytochemical enrichment of broccoli sprout juice. Partial least square (PLS) regression analysis was used to predict the biological effect exerted on Caco-2 intestinal cells exposed to TPEN/TNF $\alpha$ from composition data (see Table 1) of six juice samples corresponding to three independent replicates of sprouts grown under two different conditions. (A) Scores plot showing the distribution of juice samples: BJ-1 to 3, juices from sprouts grown in basal conditions; EJ-1 to 3, juices from sprouts grown in enriching conditions; (B) Loadings plot showing the correlation between phytochemical descriptors (X-variables) and biological effect (Y-variable). The secondary metabolites that significantly affect response prediction are circled.

Table 2. Partial Least Square (PLS) regression model to explore the relationship between phytochemical content and protective effect on Caco2 cells of broccoli sprout juice samples.

\begin{tabular}{|c|c|c|c|c|c|c|c|c|c|}
\hline Attributes & \multicolumn{2}{|c|}{$\begin{array}{c}\text { \% Explained } \\
\text { Variance }\end{array}$} & $\begin{array}{l}\text { No. of } \\
\text { Factors }\end{array}$ & \multicolumn{2}{|c|}{ Correlation $^{a}$} & \multicolumn{2}{|c|}{ Validation $^{a}$} & \multicolumn{2}{|l|}{$\mathbf{B W}^{\mathbf{b}}$} \\
\hline & $x$ & $\mathrm{Y}$ & & $\mathrm{R}^{2}$ & RMSE & $\mathrm{R}^{2}$ & RMSE & $\begin{array}{c}\text { Positive } \\
\text { Cinnamic acid; Cryptochlorogenic acid; } \\
\text { Neochlorogenic acid; Procyanidin B2; } \\
\text { Quercetin_3_Glc; Cy_3_diGlc_5_Glc; }\end{array}$ & Negative \\
\hline TEER & $92 \%$ & $100 \%$ & 2 & 0.99 & 3.59 & 0.96 & 25.31 & $\begin{array}{c}\text { Cy_3_sinapoyl_feruloyl_diGlc_5_Glc; } \\
\text { Cy_3_feruloyl_diGlc_5_malonyl_Glc; } \\
\text { Cy_3_coumaroyl_diGlc_5_Glc; } \\
\text { Cy_3_coumaryl_diGlc_5_malonyl_Glc; } \\
\text { Cy_3_coumaryl_synapoyl_diGlc_5_malonyl_Glc; }\end{array}$ & $\begin{array}{l}\text { Synapic } \\
\text { acid }\end{array}$ \\
\hline
\end{tabular}

${ }^{a} \mathrm{R}^{2}=$ square of the Pearson correlation value; $\mathrm{RMSE}=$ Root mean square error; ${ }^{\mathrm{b}}$ List of chemical compounds with significant positive and negative weighted regression coefficients (BW) with TEER. 


\section{Discussion}

Brassicaceae are a good source of many phytochemicals with health-related activity, and dietary consumption of Brassica vegetables has been associated with a reduction in the incidence of several pathological conditions including cancers and several chronic inflammatory diseases [23,36-38]. Both the profile and the amount of these phytochemicals are strongly affected by the genotype (different species/varieties) but also by environmental conditions during plant growth. It has been shown in different Brassicaeae that several nutrients [39], bioactives [27], and antioxidant capacity [40] are higher in sprouts grown in the light compared to those grown in the dark. Furthermore, the application of biotic and abiotic stress factors during growth, such as extreme temperatures, saline or osmotic stress, elicitors or hormones involved in the plant defense response, further increases the content of bioactive molecules, including GLSs, vitamins and phenolics [41-43]. In this work, sprouts where chosen as they are naturally enriched in bioactive molecules compared to the corresponding mature vegetable [18], they can be grown under fully controlled environmental conditions, and can easily be treated with elicitors to deliberately and specifically modify their phytochemical content. We found that treatment with sucrose that had been previously reported to elicit the accumulation of glucosinolate and phenolic compounds and to trigger the synthesis of anthocyanins in broccoli sprouts [43-45] provides the most significant overall effect on phytochemical composition of broccoli sprouts [13].

In this study, we aimed to evaluate the potential improvement of health-related biological activities associated with the compositional changes induced in broccoli sprouts by elicitation with sucrose. The assessment of the health-related effects of conventional, organic or novel foods is a very difficult and controversial task. Most studies suggesting beneficial effects of vegetable consumption have been performed with isolated phytochemicals, while it is increasingly accepted that it is the complex mixture of different nutrients and bioactive components acting on many different targets that make food, rather than single nutrients/bioactives, effective in reducing the risk of developing chronic and degenerative diseases and cancer [46,47]. In addition, cumulative and synergic effects of nutrient and bioactive secondary metabolites have frequently been reported and need to be taken into account [48]. Whether using in vitro, animal or human intervention studies $[9,21]$, it is generally recognized that analytical description of the administered food is a prerequisite for any attempt at evaluating the health-related potential of a given vegetable or fruit. In fact, as plant food composition is strongly affected by many different factors, poor characterization of the food source and composition often weakens the conclusions drawn from published studies [9,21].

We have used an aqueous juice obtained from sprouts grown from the same seeds under highly controlled conditions, in order to obtain two different but well-defined and reproducible profiles in certain classes of phytochemicals. Metabolic fingerprinting of juices by targeted and untargeted metabolomics confirmed that the growth conditions applied determined both qualitative and quantitative changes in the molecular phenotype of basal and enriched juices. In particular, we observed that EJ was highly enriched in anthocyanins (as also shown by the color of the juice) and contained significantly higher levels of 14 phenolic acids and flavonoids with respect to BJ. This observation is in agreement with the previously reported induction of total phenolic compounds and anthocyanins in sprouts treated with sucrose [13,44,45]. An inverse trend was observed only for four phenolics (sinapic acid, syringic acid, 4-aminobenzoic acid, and syringaldehyde). Despite the reduction in EJ, sinapic acid represented the major phenolic compound in both BJ and EJ, confirming its predominance in Brassica [49,50]. All the anthocyanins found belonged to the cyanidin group and, except for the non-acylated Cy-3-dGlc-5-Glc, presented one or two aromatic groups (sinapic, p-coumaric, ferulic or caffeic acid) conjugated to the $\mathrm{C} 3$ sugar. In addition, half of them presented an aliphatic malonyl group attached to the C5 sugar. Remarkably, a conspicuous fraction of the anthocyanins in EJ were acylated with a synapoyl group, suggesting that free sinapic acid decrease in EJ might have been due to its conjugation to newly synthetized anthocyanins upon sucrose-induction. Although a similar anthocyanin pattern has previously been reported for Brassicaceae, some compounds were, to the best of our knowledge, identified for the first time in 
broccoli sprouts $[51,52]$. The increased stability of acylated anthocyanins $[53,54]$ and their potential anti-hyperglycemic effect due to inhibition of $\alpha$-amylase activity [55] make these compounds very attractive for food quality-improvement applications.

Health-promoting foods should enhance the ability of the organism to preserve homeostasis in order to cope with environmental changes and stresses that continuously challenge its functional equilibrium. Thus experimental models aimed at the assessment of the biological activity and the potential protective effects of food or food extracts should reproduce an imbalanced physiological state that can be modulated by the addition of the food or food extract under investigation. A protective role of food bioactives has been reported in the physiological regulation of the inflammatory processes that are involved in the onset of several chronic pathologies $[1,16,56]$. Cultured cell models (monocytes, macrophages, endothelial cells, etc.) reproducing inflammatory conditions by stimulation with cytokines or lipopolysaccharide (LPS) have previously been used to test the activity of various types of food extracts, semi-purified fractions or single purified bioactive molecules [57-59]. However, the gastro-intestinal mucosa is the principal tissue that interacts with the food matrix and intestinal bioavailability and metabolism represent important determinants for the activity of food bioactives [60-62]. The human intestinal Caco-2 cell line has extensively been employed over the last 20 years as a reliable in vitro tool for predicting intestinal absorption and metabolism of nutrients and drugs. Differentiated Caco-2 cells have also been used to assess the bioactivity of apple peel and cranberry phenolic fractions to counteract oxidative (200 $\mu \mathrm{M}$ Fe-ascorbate for $6 \mathrm{~h})$ [32] or inflammatory stress ( $200 \mu \mathrm{M}$ LPS for $6 \mathrm{~h}$ ) [33], respectively. Similarly, the ability of Artemisia annua tea infusions [63] and of single purified phenolic compounds [64] to modulate the response to a cocktail of pro-inflammatory substances was tested on differentiated Caco-2 cells. We previously described a new Caco-2 cell inflammation model, based on the observation that depletion of intracellular zinc, caused by application of the zinc chelator TPEN, affects the response to the inflammatory citokine TNF $\alpha$ and shifts intestinal cell fate from survival to death [25]. Interestingly, clinical observations indicate that zinc supplements ameliorate Crohn's disease symptoms and decrease intestinal permeability in experimental colitis, suggesting that the TPEN/TNF $\alpha$ Caco-2 cell inflammation model [25] reproduces mechanisms occurring in vivo, and may thus have physiological relevance. We therefore took advantage of this experimental model to compare the bioactivity of basal and enriched broccoli sprout juices. Pre-incubation with both juices ameliorated the loss of epithelial cells' integrity induced by TPEN/TNF $\alpha$, indicating that pre-incubation with the juice increased the cellular capacity to respond to an inflammatory stress. In addition, we report that juices produced from elicited sprouts were more effective in providing cell protection. Interestingly, broccoli sprout juices, prepared under the same controlled conditions used in this study, were also shown to be protective in a cellular model of Alzheimer's disease and in Spontaneously Hypertensive Stroke Prone rats $[65,66]$.

In the field of food science and technology, multivariate statistical analysis has been applied to study the quality, authenticity and geographical origin of different food samples [67], and has recently proved useful for the analysis of fruit juices [68]. By using PLSR, we developed a model to correlate cell protection (expressed as maintenance of high TEER) and bioactive content in our experimental system. This model successfully discriminated juice samples obtained from broccoli sprouts grown in different conditions (BJ vs. EJ) and highlighted reproducibility of independent juices prepared from sprouts grown under the same conditions. In addition, the model identified important phenolic compounds, including quercetin-3-Glc, cryptochlorogenic, neochlorogenic and cinnamic acid and several anthocyanins that significantly correlated to the cell protection effect. Interestingly, anthocyanins have been associated with anti-inflammatory effects both in vivo and in vitro, due to the coordinated induction of the expression of enzymes involved in both cellular antioxidant defenses and attenuation of the inflammatory response $[6,69,70]$. Moreover, quercetin glycosides and cinnamic acids have also been described to possess anti-inflammatory, and antioxidant properties in different experimental models $[6,58,71]$. SFN, frequently invoked to be the principal bioactive compound in broccoli $[16,17]$, was present at similar levels in EJ and BJ and did not appear to correlate with the 
protective efficacy of the juices in our inflamed Caco-2 model. However, a contribution of SFN in this cell system cannot be excluded as it has been shown that it can act synergistically with quercetin on gene regulation [72], and that the combination of these two substances is more effective than either compound alone, in different cell lines [73-75].

\section{Materials and Methods}

\subsection{Broccoli Sprouts' Growth and Juice Preparation}

Broccoli seeds (Brassica oleracea L. var. botrytis subvar. cymosa) were purchased from SUBA \& UNICO (Longiano, FC, Italy). Seeds were surface sterilized by soaking for $15 \mathrm{~min}$ in $2 \%$ sodium hypochlorite under shaking, then drained and rinsed 10 times with distilled water. After soaking in distilled water for $16-18 \mathrm{~h}$ at $21{ }^{\circ} \mathrm{C}$, seeds were rinsed in distilled water and transferred in the germination cylinder of Vitaseed sprouter (SUBA \& UNICO) filled with distilled water. Sprouts were grown at $21{ }^{\circ} \mathrm{C}$ and $70 \%$ humidity in a plant growth chamber (Weiss Gallenkamp, Loughborough, United Kingdom) equipped with PHILIPS Master TL-D 36W/840 cool-white fluorescent tubes providing a photosynthetic photon flux density of $110 \mathrm{mmol} \mathrm{m}^{-2} \mathrm{~s}^{-1}$. Sprouts were grown in the dark for 5 days (basal condition). For the enriching condition, sprouts were grown under a long day (16 h light/ $8 \mathrm{~h}$ dark cycle) light regime and, after 3 days, water was replaced by $176 \mathrm{mM}$ sucrose and growth was continued for two more days. The 5-day-old sprouts were rapidly but gently collected from the germination cylinder, weighted and immediately squeezed with a mechanical press (Angel 8500S, Living Juice srl, Lecco, LC, Italy). The juice was collected in ice-cold tubes, cleared by centrifugation ( $30 \mathrm{~min}, 3300 \times \mathrm{g}, 4^{\circ} \mathrm{C}$ ) and aliquots were immediately frozen in liquid nitrogen and stored at $-80{ }^{\circ} \mathrm{C}$ until further analysis. Three batches of each type of juice obtained from three independent sprout growths (biological replicates) were used for all subsequent analysis.

\subsection{Chemicals}

Solvents used for extraction and the high-performance liquid chromatography (HPLC)-grade methanol were of high purity (Carlo Erba, Milano, Italy). HPLC-grade water $(18 \mathrm{~m} \Omega$ ) was prepared using a Millipore (Bedford, MA, USA) Milli-Q purification system. Folin and Ciocalteau's phenol reagent, gallic acid, $(+)$ catechin, aluminum chloride, sodium nitrite, HPLC-grade acetonitrile and formic acid were from Sigma-Aldrich (St. Louis, MO, USA).

\subsection{High-Resolution Untargeted Analysis}

Untargeted metabolomic analysis was performed according to the method of Rochfort et al. with minor modification [76]. The analysis was performed using a Dionex Ultimate 3000 (Thermo Scientific, Waltham, MA, USA) chromatographic system coupled with LTQ Orbitrap XL (Thermo Scientific). Opportunely diluted samples were injected into a Synergi Fusion $2.0 \times 100 \mathrm{~mm}, 2.5 \mu \mathrm{m}$ column (Phenomenex, Torrance, CA, USA) protected by Security Guard ULTRA UHPLC C18, $2.1 \mathrm{~mm}$ precolumn, at flow rate of $0.4 \mathrm{~mL} / \mathrm{min}$. Mobile phase A was water containing $0.1 \%$ formic acid, while mobile phase $\mathrm{B}$ was acetonitrile containing $0.1 \%$ formic acid (phase B). Elution gradient was: 95\% A the first minute, 55:45 (A:B) in $12 \mathrm{~min}$, from 55:45 (A:B) to 20:80 (A:B) in 2 min. The column was kept at $30^{\circ} \mathrm{C}$. Mass spectra were registered in positive and negative ion mode using resolving power for MS scan 30,000. Capillary temperature of electrospray was $320^{\circ} \mathrm{C}$, sheath gas flow 35 and auxiliary gas flow 5 . Source voltage was $3.5 \mathrm{kV}$ and $5.0 \mathrm{kV}$ for negative and positive mode, respectively. Data were processed using Sieve 2.0 (Thermo Scientific) software. Framing was set to $10 \mathrm{ppm}$ mass window ranging from 50 to $700 \mathrm{Da}$. Time width of the frames was $1 \mathrm{~min}$ ranging from 0 to $20 \mathrm{~min}$. In order to optimize processing time and computer processing power, the maximum of frames was set to 5000 . 


\subsection{Total Polyphenol, Flavonoid, and Anthocyanin Content}

The total polyphenol content was determined by the Folin-Ciocalteu method using gallic acid for calibration curve and absorbance values of samples were converted to gallic acid equivalents (GAE) [77].

The total flavonoid content was determined by using a colorimetric method described previously [78]. (+)Catechin was used as reference compound for calibration curve and absorbance values of samples were converted to catechin equivalents.

The total anthocyanin content was determined by a spectrophotometric method according to Rapisarda et al. [79]. An aliquot of juice $(0.1 \mathrm{~mL})$ was diluted to $1.4 \mathrm{~mL}$ using a $80 / 20(\mathrm{v} / \mathrm{v})$ mixture of $95 \%$ ethanol and $37 \% \mathrm{HCl}$. Absorbance of resulting solution was measured at 420 , 530, and $620 \mathrm{~nm}$ against a blank. Concentration of anthocyanins was calculated by the equation $\mathrm{C}(\mathrm{mg} / \mathrm{L})=\mathrm{Net}_{\mathrm{Abs}} \mathrm{S}_{30} /$ slope $\times \mathrm{DF}$ where Net $\mathrm{Abs}_{530}$ is given by $\mathrm{Abs}_{530}-\left(\mathrm{Abs}_{420}+\mathrm{Abs}_{620}\right) / 2$, slope is the angular coefficient of a calibration line of Net $\mathrm{Abs}_{530}$ of standard solutions of cyanidin-3-glucoside in $80 / 20$ solvent mixture, and DF is the dilution factor.

\subsection{Phenolics Profiling}

Samples of broccoli sprout juices were thawed on ice and diluted with methanol (1:1). Rosmarinic acid (RA) and malvidin 3-glucoside (Mal 3-Glu) were used as internal standards, and final concentrations were $2 \mathrm{mg} / \mathrm{L}$ and $10 \mathrm{mg} / \mathrm{L}$, respectively. Samples were sonicated for $10 \mathrm{~min}$, centrifuged for $10 \mathrm{~min}$ at 10,000 RPM, filtered over $0.22 \mathrm{~mm}$ Polyvinylidene Fluoride (PVDF) filters and injected into chromatographic system.

In order to quantify different phenolic compounds, a target metabolomic method was used using an Acquity UPLC connected to a Xevo TQMS (Waters, Milford, MA, USA) [80]. Reversed phase separation was performed with $100 \mathrm{~mm} \times 2.1 \mathrm{~mm}, 1.8 \mu \mathrm{m}$ column (Acquity HSS T3, Waters), protected with an Acquity UPLC HSS T3 $1.8 \mathrm{~mm}$ precolumn (Waters). Mobile phases were composed of $0.1 \%$ formic acid (FA) in water (phase A) and $0.1 \%$ of FA in Acetonitrile (phase B). Flow was set at $0.4 \mathrm{~mL} / \mathrm{min}$. Linear gradient started from $5 \% \mathrm{~B}$ to $20 \% \mathrm{~B}$ in $3 \mathrm{~min}$, followed by isocratic step at $20 \% \mathrm{~B}$ for $1.3 \mathrm{~min}$ and two additional steps, from $20 \%$ to $45 \% \mathrm{~B}$ in $4.7 \mathrm{~min}$ and from $45 \%$ to $100 \%$ B in $2 \mathrm{~min}$. Mass spectrometry detection of phenols was performed with electrospray ionization (ESI) in positive and negative modes as described by Vrhovsek et al. [80].

For the detection of anthocyanins, we followed the method of Arapitsas et al. with minor modification [81]. The analysis was performed using an Acquity UPLC connected to a Xevo TQMS, equipped with an Acquity UPLC BEH C18 $1.7 \mu \mathrm{m}, 2.1 \mathrm{~mm} \times 150 \mathrm{~mm}$ column (Waters), and an Acquity UPLC BEH C18 $1.7 \mathrm{~mm}$ procolumn (Waters). Mobile phases were composed of $5 \%$ FA in water (A) and 5\% FA in methanol (B). Identification of individual anthocyanins was based on MRM transitions and retention times as previously reported [51,81]. Results were expressed as cyanidin 3,5-diglucoside equivalents.

Processing of raw data sets was performed with the help of Mass Lynx Target Lynx Application Manager (Waters).

\subsection{Glucosinolate, Sulforaphane and Sulforaphane Nitrile Determination}

GLSs were determined in broccoli sprout juices by a HPLC MS/MS method according to Maldini et al. [27]. Fourteen GLSs were analyzed, namely gluconapin, progoitrin, sinigrin, gluconapoleiferin, glucoraphanin, glucoiberin, glucoerucin glucocheirolin, glucoiberverin, glucoalysin, 4-methoxyglucobrassicin, neoglucobrassicin, 4-hydroxyglucobrassicin, glucobrassicin. Sulforaphane (SFN) determination was performed using an HPLC system (Perkin-Elmer, Waltham, MA, USA) interfaced with an Applied Biosystems (Foster City, CA, USA) API3200 Q-Trap spectrometer. Quantitative on-line HPLC-ESI-MS/MS analyses were performed using mass spectrometer in negative (for GLSs) and in positive (for SFN and SFN-nitrile) Multiple Reaction Monitoring (MRM) mode. 
The API 3200 ES source was tuned by infusing a standard solution of SFN $(1 \mu \mathrm{g} / \mathrm{mL}$ in methanol 50\%) into the source at a flow rate of $10 \mu \mathrm{L} / \mathrm{min}$. The optimized parameters were: declustering potential $45 \mathrm{eV}$, entrance potential $5 \mathrm{eV}$, collision energy $18 \mathrm{eV}$; fragmentation reactions selected for SFN and SFN-nitrile were $178 \rightarrow 14(\mathrm{CE}=18 ; \mathrm{CXP}=4 ; \mathrm{CEP}=14)$ and $146 \rightarrow 7(\mathrm{CE}=25 ; \mathrm{CXP}=4 ; \mathrm{CEP}=13)$, respectively. The source temperature was held at $400{ }^{\circ} \mathrm{C}$ and the voltage applied was 5500 . The dwell time was $120 \mathrm{~ms}$.

Juice samples were opportunely diluted in $\mathrm{H}_{2} \mathrm{O}$ with $0.1 \%$ formic acid, filtered, injected $(10 \mu \mathrm{L})$ into a Luna C18 column (Phenomenex, Torrance, CA, USA) $(150 \times 2.1 \mathrm{~mm}$ i.d., $5 \mu \mathrm{m})$ and eluted at flow rate of $0.3 \mathrm{~mL} / \mathrm{min}$. Mobile phase A was $\mathrm{H}_{2} \mathrm{O}$ containing $0.1 \%$ formic acid while mobile phase $\mathrm{B}$ was acetonitrile containing $0.1 \%$ formic acid. Elution gradient was: 100\% A, 20:80 (A:B) in $20 \mathrm{~min}$, from 20:80 (A:B) to 0:100 (A:B) in $1 \mathrm{~min}$. The column was kept at $25^{\circ} \mathrm{C}$, using a Peltier Column Oven Series 200 (Perkin Elmer). Data acquisition and processing were performed using Analyst software 1.5.1. Both SFN and SFN-nitrile concentration was calculated over an external standard curve of SFN.

\subsection{Cell Culture}

The Caco-2 cell line, obtained from INSERM (Paris, France), was routinely sub-cultured at $50 \%$ density [31], and was maintained at $37{ }^{\circ} \mathrm{C}$ in a $90 \%$ air- $10 \% \mathrm{CO}_{2}$ atmosphere in Dulbecco Minimum Essential Medium (DMEM) containing $25 \mathrm{mM}$ glucose, $3.7 \mathrm{~g} / \mathrm{L} \mathrm{NaHCO} 3,4 \mathrm{mM}$-glutamine, $1 \%$ nonessential amino acids, $100 \mathrm{U} / \mathrm{L}$ penicillin, $100 \mu \mathrm{g} / \mathrm{L}$ streptomycin (complete medium), supplemented with 10\% heat-inactivated fetal bovine serum (FBS Hyclone Laboratories, Logan, UT, USA). All reagents were from Sigma-Aldrich (Milan, Italy).

For differentiation, cells were seeded on polycarbonate filters, $12 \mathrm{~mm}$ diameter, $0.4 \mu \mathrm{m}$ pore diameter (Transwell, Corning Inc. Lowell, MA, USA) at a density of $3.5 \times 10^{5} \mathrm{cells} / \mathrm{cm}^{2}$ in complete medium supplemented with 10\% FBS in both AP and BL compartments for two days to allow the formation of a confluent cell monolayer. From day 3 after seeding, cells were transferred to complete medium in both compartments, supplemented with $10 \%$ FBS only in the BL compartment and allowed to differentiate for 21 days with regular medium changes three times a week [30].

\subsection{Measure of Monolayer Integrity}

To determine the effects of the treatments on the permeability of intestinal tight junctions and the integrity of the cell monolayer in Caco-2 cells, Trans-Epithelial Electrical Resistance (TEER) was measured at $37^{\circ} \mathrm{C}$ using the voltmeter apparatus Millicell (Millipore , Merck Group, Darmstadt, Germany) provided with $\mathrm{Ag} / \mathrm{AgCl}$ electrodes, as previously described [82]. TEER was expressed as $\Omega \cdot \mathrm{cm}^{2}=(\Omega$ cells $-\Omega$ filter $) \cdot$ A, where $\Omega$ cells is the monolayer resistance, $\Omega$ filter is the resistance of the filter by itself and $\mathrm{A}$ is the filter area $\left(\mathrm{cm}^{2}\right)$.

\subsection{Experimental Intestinal Cell Model}

Prior to each experiment, differentiated Caco-2 cells were pre-incubated for $14 \mathrm{~h}$ in DMEM without addition of FBS (experimental medium), with or without $250 \mu \mathrm{L} / \mathrm{mL}$ sprout juice in the apical (AP) compartment. To achieve marginal zinc depletion, cells were incubated in experimental medium containing $20 \mu \mathrm{M} \mathrm{N}, N, N^{\prime}, N^{\prime}$-tetrakis (2-pyridylmethyl) ethylene-diamine (TPEN) (Sigma-Aldrich Co., Milan, Italy) for $2 \mathrm{~h}$. Following TPEN removal, they were exposed to fresh medium containing $2 \mathrm{ng} / \mathrm{mL}$ $\mathrm{TNF} \alpha$ (Sigma-Aldrich Co., Milan, Italy), as previously described [25].

\subsection{Statistical Analysis}

All the analyses were performed using three juices for each condition, obtained from independent sprout growths (biological replicates). All analytical measurements and cell culture experiments were performed in triplicate and statistical analyses were performed using Microsoft Office Excel 2011 upgraded with XLSTAT (ver. 4 March 2014). Data were expressed as mean \pm SD and analyzed by one-way ANOVA followed by Fischer post hoc test. 
For multivariate data analysis, Partial Least Square Regression (PLSR) was performed with Unscrambler v 10.2 (CAMO Software AS, Oslo, Norway) using the Non-Linear Iterative Partial Least Squares (NIPALS) algorithm. Targeted chemical data constituted the independent X-block of variables, while the cell protection attributes represented the dependent $Y$-variable. Data were normalized by mean centering using the $1 /$ (standard deviation) transformation to ensure that all variables had equal potential influence. The calibration model was validated by full cross-validation. Weighted regression coefficients (BW) for the relationships between chemical and biological variables were determined by applying Martens' uncertainty test option. Throughout all data analysis, effects were considered to be significant at a level of $p<0.05$.

\section{Conclusions}

Brassica oleracea sprout juices were shown to confer protection to an in vitro model of inflamed human intestinal epithelium based on Caco- 2 cells treated with TNF- $\alpha$ under marginal zinc deprivation. In addition, nutraceutical improvement of the juice obtained through elicitation of the sprouts increased the protective potential of the juice. By combining controlled growth and metabolic profiling of the sprouts with multivariate analysis, we demonstrate that the protective effect is reproducible and is correlated to a number of bioactive molecules whose levels are indicative of a functional enrichment of the food matrix. While the phytochemicals that significantly correlated with the protective effect can be used as reliable descriptors of the biological potential of BJ and EJ juices, further investigation is needed to demonstrate that these molecules are causally related to the bioactivity observed in Caco- 2 cells.

Acknowledgments: We thank Kariklia Pascucci for her kind support in the daily lab work. This work was supported by the Italian Ministry for the Agricultural, Food and Forestry Policies (www.politicheagricole.it) with the grants NUTRIGEA (DM 30281 23/12/2009) and NUME (DM 3688/7303/08) and by the Italian Ministry of Education, University and Research (www.istruzione.it) with the grant PROS.IT-CL.A.N. (CTN01_002230_413096).

Author Contributions: S.B., G.M., Y.S., G.R., S.F., C.M., F.N., C.S., and F.M. conceived and designed the experiments; S.F., G.R., C.R., K.T., F.N., M.M., M.N., A.M.G., and S.B. performed the experiments; G.R., F.N., Y.S., S.B., E.M., and K.T., analyzed the data; F.M. contributed reagents/materials/analysis tools; S.B., Y.S., G.R., and F.N. wrote the paper.

Conflicts of Interest: The authors declare no conflict of interest.

\section{References}

1. Boeing, H.; Bechthold, A.; Bub, A.; Ellinger, S.; Haller, D.; Kroke, A.; Leschik-Bonnet, E.; Muller, M.J.; Oberritter, H.; Schulze, M.; et al. Critical review: Vegetables and fruit in the prevention of chronic diseases. Eur. J. Nutr. 2012, 51, 637-663.

2. Leenders, M.; Sluijs, I.; Ros, M.M.; Boshuizen, H.C.; Siersema, P.D.; Ferrari, P.; Weikert, C.; Tjønneland, A.; Olsen, A.; Boutron-Ruault, M.C. Fruit and Vegetable Consumption and Mortality European Prospective Investigation Into Cancer and Nutrition. Am. J. Epidemiol. 2013, 178, 590-602. [PubMed]

3. Wang, X.; Ouyang, Y.; Liu, J.; Zhu, M.; Zhao, G.; Bao, W.; Hu, F.B. Fruit and vegetable consumption and mortality from all causes, cardiovascular disease, and cancer: Systematic review and dose-response meta-analysis of prospective cohort studies. BMJ 2014, 349, g4490.

4. Hu, D.; Huang, J.; Wang, Y.; Zhang, D.; Qu, Y. Fruits and Vegetables Consumption and Risk of Stroke: A Meta-Analysis of Prospective Cohort Studies. Stroke 2014, 45, 1613-1619.

5. Traka, M.; Mithen, R. Glucosinolates, isothiocyanates and human health. Phytochem. Rev. 2009, 8, 269-282.

6. Nile, S.H.; Park, S.W. Edible berries: Bioactive components and their effect on human health. Nutrition 2014, 30, 134-144. [PubMed]

7. Rodrigo, R.; Libuy, M.; Feliu, F.; Hasson, D. Polyphenols in disease: From diet to supplements. Curr. Pharm. Biotechnol. 2014, 15, 304-317. [PubMed]

8. Finley, J.W. Proposed criteria for assessing the efficacy of cancer reduction by plant foods enriched in carotenoids, glucosinolates, polyphenols and selenocompounds. Ann. Bot. 2005, 95, 1075-1096. 
9. Fahey, J.W.; Talalay, P.; Kensler, T.W. Notes from the field: “Green” chemoprevention as frugal medicine. Cancer Prev. Res. 2012, 5, 179-188.

10. Hall, R.D. Plant metabolomics: From holistic hope, to hype, to hot topic. New Phytol. 2006, 169, $453-468$.

11. Cheynier, V.; Comte, G.; Davies, K.M.; Lattanzio, V.; Martens, S. Plant phenolics: Recent advances on their biosynthesis, genetics, andecophysiology. Plant Physiol. Biochem. 2013, 72, 1-20. [CrossRef] [PubMed]

12. Baenas, N.; García-Viguera, C.; Moreno, D.A. Biotic elicitors effectively increase the glucosinolates content in Brassicaceae sprouts. J. Agric. Food Chem. 2014, 62, 1881-1889. [PubMed]

13. Natella, F.; Maldini, M.; Nardini, M.; Azzini, E.; Foddai, M.S.; Giusti, A.M.; Baima, S.; Morelli, G.; Scaccini, C. Improvement of the nutraceutical quality of broccoli sprouts by elicitation. Food Chem. 2016, 201, 101-109. [PubMed]

14. Vasanthi, H.R.; Mukherjee, S.; Das, D.K. Potential health benefits of broccoli- a chemico-biological overview. Mini Rev. Med. Chem. 2009, 9, 749-759.

15. Jahangir, M.; Kim, H.K.; Choi, Y.H.; Verpoorte, R. Health-affecting compounds in Brassicaceae. Compr. Rev. Food Sci. Food Saf. 2009, 8, 31-43. [CrossRef]

16. Wagner, A.E.; Terschluesen, A.M.; Rimbach, G. Health promoting effects of brassica-derived phytochemicals: From chemopreventive and anti-inflammatory activities to epigenetic regulation. Oxid. Med. Cell. Longev. 2013, 2013, 964539. [CrossRef]

17. Houghton, C.A.; Fassett, R.G.; Coombes, J.S. Sulforaphane: Translational research from laboratory bench to clinic. Nutr. Rev. 2013, 71, 709-726. [CrossRef]

18. Fahey, J.W.; Zhang, Y.; Talalay, P. Broccoli sprouts: An exceptionally rich source of inducers of enzymes that protect against chemical carcinogens. Proc. Natl. Acad. Sci. USA 1997, 94, 10367-10372. [PubMed]

19. Bhandari, S.; Jo, J.; Lee, J. Comparison of Glucosinolate Profiles in Different Tissues of Nine Brassica Crops. Molecules 2015, 20, 15827-15841.

20. Hanlon, P.R.; Barnes, D.M. Phytochemical Composition and Biological Activity of 8 Varieties of Radish (Raphanus sativus L.) Sprouts and Mature Taproots. J. Food Sci. 2011, 76, C185-C192. [PubMed]

21. Traka, M.H.; Mithen, R.F. Plant science and human nutrition: Challenges in assessing health-promoting properties of phytochemicals. Plant Cell 2011, 23, 2483-2497. [PubMed]

22. Jiang, Y.; Wu, S.H.; Shu, X.O.; Xiang, Y.B.; Ji, B.T.; Milne, G.L.; Cai, Q.; Zhang, X.; Gao, Y.T.; Zheng, W.; et al. Cruciferous vegetable intake is inversely correlated with circulating levels of proinflammatory markers in women. J. Acad. Nutr. Diet. 2014, 114, 700-708.e2. [CrossRef]

23. Medina, S.; Domínguez-Perles, R.; Moreno, D.A.; García-Viguera, C.; Ferreres, F.; Gil, J.I.; Gil-Izquierdo, Á. The intake of broccoli sprouts modulates the inflammatory and vascular prostanoids but not the oxidative stress-related isoprostanes in healthy humans. Food Chem. 2015, 173, 1187-1194.

24. Lippmann, D.; Lehmann, C.; Florian, S.; Barknowitz, G.; Haack, M.; Mewis, I.; Wiesner, M.; Schreiner, M.; Glatt, H.; Brigelius-Flohé, R.; et al. Glucosinolates from pak choi and broccoli induce enzymes and inhibit inflammation and colon cancer differently. Food Funct. 2014, 5, 1073-1081.

25. Ranaldi, G.; Ferruzza, S.; Canali, R.; Leoni, G.; Zalewski, P.D.; Sambuy, Y.; Perozzi, G.; Murgia, C. Intracellular zinc is required for intestinal cell survival signals triggered by the inflammatory cytokine TNF? J. Nutr. Biochem. 2013, 24, 967-976.

26. Lee, S.G.; Kim, J.; Son, M.; Lee, E.; Park, W.; Kim, J.; Lee, S.; Lee, I. Influence of Extraction Method on Quality and Functionality of Broccoli Juice. Prev. Nutr. Food Sci. 2013, 18, 133-138. [PubMed]

27. Maldini, M.; Baima, S.; Morelli, G.; Scaccini, C.; Natella, F. A liquid chromatography-mass spectrometry approach to study "glucosinoloma" in broccoli sprouts. J. Mass Spectrom. 2012, 47, 1198-1206.

28. Delie, F.; Rubas, W. A human colonic cell line sharing similarities with enterocytes as a model to examine oral absorption: Advantages and limitations of the Caco-2 model. Crit. Rev. Ther. Drug Carr. Syst. 1997, 14, 221-286.

29. Sambuy, Y.; De Angelis, I.; Ranaldi, G.; Scarino, M.L.; Stammati, A.; Zucco, F. The Caco-2 cell line as a model of the intestinal barrier: Influence of cell and culture-related factors on Caco-2 cell functional characteristics. Cell Biol. Toxicol. 2005, 21, 1-26.

30. Ferruzza, S.; Rossi, C.; Scarino, M.L.; Sambuy, Y. A protocol for differentiation of human intestinal Caco-2 cells in asymmetric serum-containing medium. Toxicol. Vitr. 2012, 26, 8-11. 
31. Natoli, M.; Leoni, B.D.; D'Agnano, I.; D’Onofrio, M.; Brandi, R.; Arisi, I.; Zucco, F.; Felsani, A. Cell growing density affects the structural and functional properties of Caco-2 differentiated monolayer. J. Cell. Physiol. 2011, 226, 1531-1543. [PubMed]

32. Denis, M.C.; Furtos, A.; Dudonné, S.; Montoudis, A.; Garofalo, C.; Desjardins, Y.; Delvin, E.; Levy, E. Apple Peel Polyphenols and Their Beneficial Actions on Oxidative Stress and Inflammation. PLoS ONE 2013, 8, e53725.

33. Denis, M.; Desjardins, Y.; Furtos, A.; Marcil, V.; Dudonné, S.; Montoudis, A.; Garofalo, C.; Delvin, E.; Marette, A.; Levy, E. Prevention of oxidative stress, inflammation and mitochondrial dysfunction in the intestine by different cranberry phenolic fractions. Clin. Sci. 2015, 128, 197-212. [PubMed]

34. Ferruzza, S.; Scarino, M.L.; Rotilio, G.; Ciriolo, M.R.; Santaroni, P.; Muda, A.O.; Sambuy, Y. Copper treatment alters the permeability of tight junctions in cultured human intestinal Caco-2 cells. Am. J. Physiol. Gastrointest. Liver Physiol. 1999, 277, G1138-G1148.

35. Srinivasan, B.; Kolli, A.R.; Esch, M.B.; Abaci, H.E.; Shuler, M.L.; Hickman, J.J. TEER measurement techniques for in vitro barrier model systems. J. Lab. Autom. 2015, 20, 107-126. [PubMed]

36. Herr, I.; Büchler, M.W. Dietary constituents of broccoli and other cruciferous vegetables: Implications for prevention and therapy of cancer. Cancer Treat. Rev. 2010, 36, 377-383. [PubMed]

37. James, D.; Devaraj, S.; Bellur, P.; Lakkanna, S.; Vicini, J.; Boddupalli, S. Novel concepts of broccoli sulforaphanes and disease: Induction of phase II antioxidant and detoxification enzymes by enhanced-glucoraphanin broccoli. Nutr. Rev. 2012, 70, 654-665. [PubMed]

38. Jung, H.A.; Karki, S.; Ehom, N.; Yoon, M.; Kim, E.J.; Choi, J.S. Anti-Diabetic and Anti-Inflammatory Effects of Green and Red Kohlrabi Cultivars (Brassica oleracea var. gongylodes). Prev. Nutr. Food Sci. 2014, 19, 281-290.

39. Vale, A.P.; Santos, J.; Brito, N.V.; Peixoto, V.; Carvalho, R.; Rosa, E.; Oliveira, M.B.P.P. Light influence in the nutritional composition of Brassica oleracea sprouts. Food Chem. 2015, 178, 292-300.

40. Vale, A.P.; Cidade, H.; Pinto, M.; Oliveira, M.B.P.P. Effect of sprouting and light cycle on antioxidant activity of Brassica oleracea varieties. Food Chem. 2014, 165, 379-387. [PubMed]

41. Jahangir, M.; Abdel-Farid, I.B.; Kim, H.K.; Choi, Y.H.; Verpoorte, R. Healthy and unhealthy plants: The effect of stress on the metabolism of Brassicaceae. Environ. Exp. Bot. 2009, 67, 23-33.

42. Björkman, M.; Klingen, I.; Birch, A.N.E.; Bones, A.M.; Bruce, T.J.A.; Johansen, T.J.; Meadow, R.; Mølmann, J.; Seljåsen, R.; Smart, L.E.; et al. Phytochemicals of Brassicaceae in plant protection and human health-Influences of climate, environment and agronomic practice. Phytochemistry 2011, 72, 538-556.

43. Baenas, N.; García-Viguera, C.; Moreno, D. Elicitation: A Tool for Enriching the Bioactive Composition of Foods. Molecules 2014, 19, 13541-13563.

44. Guo, R.; Yuan, G.; Wang, Q. Sucrose enhances the accumulation of anthocyanins and glucosinolates in broccoli sprouts. Food Chem. 2011, 129, 1080-1087. [CrossRef] [PubMed]

45. Guo, R.; Yuan, G.; Wang, Q. Effect of sucrose and mannitol on the accumulation of health-promoting compounds and the activity of metabolic enzymes in broccoli sprouts. Sci. Hortic. (Amst.) 2011, 128, 159-165. [CrossRef]

46. Jacobs, D.R.; Tapsell, L.C. Food, not nutrients, is the fundamental unit in nutrition. Nutr. Rev. 2007, 65, 439-450. [CrossRef] [PubMed]

47. Domínguez-Perles, R.; Mena, P.; García-Viguera, C.; Moreno, D.A. Brassica foods as a dietary source of vitamin C: A review. Crit. Rev. Food Sci. Nutr. 2014, 54, 1076-1091. [CrossRef] [PubMed]

48. Di Gesso, J.L.; Kerr, J.S.; Zhang, Q.; Raheem, S.; Yalamanchili, S.K.; O’Hagan, D.; Kay, C.D.; O'Connell, M.A. Flavonoid metabolites reduce tumor necrosis factor- $\alpha$ secretion to a greater extent than their precursor compounds in human THP-1 monocytes. Mol. Nutr. Food Res. 2015, 59, 1143-1154. [PubMed]

49. Cartea, M.E.; Francisco, M.; Soengas, P.; Velasco, P. Phenolic compounds in Brassica vegetables. Molecules 2011, 16, 251-280. [CrossRef] [PubMed]

50. Milkowski, C.; Strack, D. Sinapate esters in brassicaceous plants: Biochemistry, molecular biology, evolution and metabolic engineering. Planta 2010, 232, 19-35. [PubMed]

51. Moreno, D.A.; Pérez-Balibrea, S.; Ferreres, F.; Gil-Izquierdo, Á.; García-Viguera, C. Acylated anthocyanins in broccoli sprouts. Food Chem. 2010, 123, 358-363.

52. Baenas, N.; Ferreres, F.; García-Viguera, C.; Moreno, D.A. Radish sprouts-Characterization and elicitation of novel varieties rich in anthocyanins. Food Res. Int. 2015, 69, 305-312. [CrossRef] 
53. De Pascual-Teresa, S.; Sanchez-Ballesta, M.T. Anthocyanins: From plant to health. Phytochem. Rev. 2007, 7, 281-299.

54. Giusti, M.M.; Wrolstad, R.E. Acylated anthocyanins from edible sources and their applications in food systems. Biochem. Eng. J. 2003, 14, 217-225. [CrossRef]

55. Matsui, T.; Ueda, T.; Oki, T.; Sugita, K.; Terahara, N.; Matsumoto, K. $\alpha$-Glucosidase Inhibitory Action of Natural Acylated Anthocyanins. $\alpha$-Glucosidase Inhibition by Isolated Acylated Anthocyanins. J. Agric. Food Chem. 2001, 49, 1952-1956. [PubMed]

56. Pan, M.-H.; Lai, C.-S.; Ho, C.-T. Anti-inflammatory activity of natural dietary flavonoids. Food Funct. 2010, 1 , 15-31. [CrossRef] [PubMed]

57. Risitano, R.; Currò, M.; Cirmi, S.; Ferlazzo, N.; Campiglia, P.; Caccamo, D.; Ientile, R.; Navarra, M. Flavonoid fraction of Bergamot juice reduces LPS-induced inflammatory response through SIRT1-mediated NF-кB inhibition in THP-1 monocytes. PLOS ONE 2014, 9, e107431.

58. Ma, M.-M.; Li, Y.; Liu, X.-Y.; Zhu, W.-W.; Ren, X.; Kong, G.-Q.; Huang, X.; Wang, L.-P.; Luo, L.-Q.; Wang, X.-Z. Cyanidin-3-O-Glucoside Ameliorates Lipopolysaccharide-Induced Injury Both In Vivo and In Vitro Suppression of NF-KB and MAPK Pathways. Inflammation 2015, 38, 1668-1682. [CrossRef] [PubMed]

59. Kim, Y.; Mohri, S.; Hirai, S.; Lin, S.; Goto, T.; Ohyane, C.; Sakamoto, T.; Takahashi, H.; Shibata, D.; Takahashi, N.; et al. Tomato extract suppresses the production of proinflammatory mediators induced by interaction between adipocytes and macrophages. Biosci. Biotechnol. Biochem. 2015, 79, 82-87.

60. Parada, J.; Aguilera, J.M. Food microstructure affects the bioavailability of several nutrients. J. Food Sci. 2007, 72, 21-32. [CrossRef]

61. Fernandes, I.; Faria, A.; Calhau, C.; de Freitas, V.; Mateus, N. Bioavailability of anthocyanins and derivatives. J. Funct. Foods 2014, 7, 54-66. [CrossRef]

62. Toydemir, G.; Boyacioglu, D.; Capanoglu, E.; Van Der Meer, I.M.; Tomassen, M.M.M.; Hall, R.D.; Mes, J.J.; Beekwilder, J. Investigating the transport dynamics of anthocyanins from unprocessed fruit and processed fruit juice from sour cherry (Prunus cerasus L.) across intestinal epithelial cells. J. Agric. Food Chem. 2013, 61, 11434-11441. [PubMed]

63. Melillo De Magalhães, P.; Dupont, I.; Hendrickx, A.; Joly, A.; Raas, T.; Dessy, S.; Sergent, T.; Schneider, Y.J. Anti-inflammatory effect and modulation of cytochrome $\mathrm{P} 450$ activities by Artemisia annua tea infusions in human intestinal Caco-2 cells. Food Chem. 2012, 134, 864-871. [PubMed]

64. Sergent, T.; Piront, N.; Meurice, J.; Toussaint, O.; Schneider, Y.J. Anti-inflammatory effects of dietary phenolic compounds in an in vitro model of inflamed human intestinal epithelium. Chem. Biol. Interact. 2010, 188, 659-667. [CrossRef]

65. Masci, A.; Mattioli, R.; Costantino, P.; Baima, S.; Morelli, G.; Punzi, P.; Giordano, C.; Pinto, A.; Donini, L.M.; Erme, M.; et al. Neuroprotective Effect of Brassica oleracea Sprouts Crude Juice in a Cellular Model of Alzheimer's Disease. Oxid. Med. Cell. Longev. 2015, 2015, 781938. [CrossRef] [PubMed]

66. Rubattu, S.; Di Castro, S.; Cotugno, M.; Bianchi, F.; Mattioli, R.; Baima, S.; Stanzione, R.; Madonna, M.; Bozzao, C.; Marchitti, S.; et al. Protective effects of Brassica oleracea sprouts extract toward renal damage in high-salt-fed SHRSP. J. Hypertens. 2015, 33, 1465-1479. [PubMed]

67. Berrueta, L.A.; Alonso-Salces, R.M.; Héberger, K. Supervised pattern recognition in food analysis. J. Chromatogr. A 2007, 1158, 196-214. [CrossRef] [PubMed]

68. Zielinski, A.F.; Haminiuk, C.W.I.; Nunes, C.A.; Schnitzler, E.; Van Ruth, S.M.; Granato, D. Chemical Composition, Sensory Properties, Provenance, and Bioactivity of Fruit Juices as Assessed by Chemometrics: A Critical Review and Guideline. Compr. Rev. Food Sci. Food Saf. 2014, 13, 300-316.

69. Cassidy, A.; Rogers, G.; Peterson, J.J.; Dwyer, J.T.; Lin, H.; Jacques, P.F. Higher dietary anthocyanin and flavonol intakes are associated with anti-inflammatory effects in a population of US adults. Am. J. Clin. Nutr. 2015, 102, 3-5.

70. Li, D.; Wang, P.; Luo, Y.; Zhao, M.; Chen, F. Health Benefits of Anthocyanins and Molecular Mechanisms: Update from Recent Decade. Crit. Rev. Food Sci. Nutr. 2015. [CrossRef]

71. Hadjipavlou-Litina, D.; Pontiki, E. Aryl-acetic and cinnamic acids as lipoxygenase inhibitors with antioxidant, anti-inflammatory, and anticancer activity. Methods Mol. Biol. 2015, 1208, 361-377.

72. Das, N.; Berhow, M.A.; Angelino, D.; Jeffery, E.H. Camelina sativa Defatted Seed Meal Contains Both Alkyl Sulfinyl Glucosinolates and Quercetin That Synergize Bioactivity. J. Agric. Food Chem. 2014, 62, 8385-8391. [CrossRef] [PubMed] 
73. Nair, S.; Hebbar, V.; Shen, G.; Gopalakrishnan, A.; Khor, T.O.; Yu, S.; Xu, C.; Kong, A.-N. Synergistic effects of a combination of dietary factors sulforaphane and (-)epigallocatechin-3-gallate in HT-29 AP-1 human colon carcinoma cells. Pharm. Res. 2008, 25, 387-399. [PubMed]

74. Appari, M.; Babu, K.R.; Kaczorowski, A.; Gross, W.; Herr, I. Sulforaphane, quercetin and catechins complement each other in elimination of advanced pancreatic cancer by miR-let-7 induction and K-ras inhibition. Int. J. Oncol. 2014, 45, 1391-1400. [PubMed]

75. Pradhan, S.J.; Mishra, R.; Sharma, P.; Kundu, G.C. Quercetin and sulforaphane in combination suppress the progression of melanoma through the down-regulation of matrix metalloproteinase. Exp. Ther. Med. 2010, 1, 915-920. [PubMed]

76. Rochfort, S.J.; Trenerry, V.C.; Imsic, M.; Panozzo, J.; Jones, R. Class targeted metabolomics: ESI ion trap screening methods for glucosinolates based on MSn fragmentation. Phytochemistry 2008, 69, 1671-1679.

77. Kapasakalidis, P.G.; Rastall, R.A.; Gordon, M.H. Extraction of polyphenols from processed black currant (Ribes nigrum L.) residues. J. Agric. Food Chem. 2006, 54, 4016-4021.

78. Dewanto, V.; Wu, X.; Adom, K.K.; Liu, R.H. Thermal processing enhances the nutritional value of tomatoes by increasing total antioxidant activity. J. Agric. Food Chem. 2002, 50, 3010-3014.

79. Rapisarda, P.; Fanella, F.; Maccarone, E. Reliability of Analytical Methods for Determining Anthocyanins in Blood Orange Juices. J. Agric. Food Chem. 2000, 48, 2249-2252. [CrossRef]

80. Vrhovsek, U.; Masuero, D.; Gasperotti, M.; Franceschi, P.; Caputi, L.; Viola, R.; Mattivi, F. A versatile targeted metabolomics method for the rapid quantification of multiple classes of phenolics in fruits and beverages. J. Agric. Food Chem. 2012, 60, 8831-8840. [PubMed]

81. Arapitsas, P.; Perenzoni, D.; Nicolini, G.; Mattivi, F. Study of Sangiovese Wines Pigment Profile by UHPLC-MS/MS. J. Agric. Food Chem. 2012, 60, 10461-10471. [PubMed]

82. Ferruzza, S.; Scarino, M.L.; Gambling, L.; Natella, F.; Sambuy, Y. Biphasic effect of iron on human intestinal Caco-2 cells: Early effect on tight junction permeability with delayed onset of oxidative cytotoxic damage. Cell Mol. Biol. 2003, 49, 89-99. [PubMed]

(C) 2016 by the authors; licensee MDPI, Basel, Switzerland. This article is an open access article distributed under the terms and conditions of the Creative Commons Attribution (CC-BY) license (http://creativecommons.org/licenses/by/4.0/). 